\title{
Uma nova espécie de Dicymbe Spruce ex Bentham (Leguminosae-Caesalpinioideae) para a Amazônia
}

\author{
William A. Rodrigues (*)
}

\section{RESUMO}

Dicymbe arenicola $W$. Rodrigues (Leguminosae Caesalpinioideae), espécie até hoje só conhecida de uma campina de pedras das cercanias de Manaus, Amazonas, Brasil, é descrita neste trabalho como espécie nova.

Dicymbe arenicola W. Rodrigues, n. sp. (Fig. 1)

Species maxime affinis $D$. spicatae Cowan, quae differt foliis minoribus, foliolis vulgo 2-5jugatis, ad basim subcordatis, ad apicem 1 glandula ornatis, laminis petalorum adaxialium suborbiculatis vel obovatis, staminibus 8-10, filamentis in parte inferiore villosulis, ovariis dense pilosis.

Árvore pequena, raminhos mais jovens esparsa e diminutamente estrigulosos, cilíndricos, estípulas caducas; folhas imparipinadas ou paripinadas, em geral com 2-5 pares de folíolos, 5-10 folíolos íraramente 1), pecíolos de $8-20 \mathrm{~mm}$ de comprimento, escassamente estrigulosos, raque de $25-70 \mathrm{~mm}$ de comprimento, esparsamente estrigulosos, pilosidade esta estendendo-se ao longo da nervura central, na página inferior do folíolo; lâminas dos folíolos com $20-80 \mathrm{~mm}$ de comprimento, $10-43 \mathrm{~mm}$ de largura, ovais, coriáceas, assimétricas e subcordadas na base, às vezes obtusas, especialmente nos folíolos terminais, acuminadas no ápice, acumem em geral com uma glândula apical, reticulado-venosas em ambas as páginas, a inferior em geral com pontuações glandulares diminutas e escassos pelos deitados e retos, costa plana na página superior e saliente na inferior. Inflorescências terminais até cerca de $18 \mathrm{~cm}$ de comprimento, paniculadas, os raminhos laterais racemosos, até $6,5 \mathrm{~cm}$ de comprimento, os eixos densamente estri- gulosos; brácteas triangulares, cerca de 1,5-2 $\mathrm{mm}$ de comprimento, côncavas, externamente estrigulosas, internamente glabras e estriadas, cedo decíduas; bractéolas espessamente coriáceas, côncavas, aderentes à metade inferior do hipanto, a parte livre com $10-13 \mathrm{~mm}$ de comprimento, $4-5 \mathrm{~mm}$ de largura, obovado-oblongas, densamente estrigulosas externamente, esparsa e diminutamente pubescentes internamente, apicalmente com uma glândula truncada e longo-estipitada, o estipe até cerca de $2 \mathrm{~mm}$ de comprimento, estriguloso; hipanto assimetricamente cilíndrico, com cerca de $5-6 \mathrm{~mm}$ de comprimento, a parte superior cerca de $3 \mathrm{~mm}$ acima das bractéolas, glabra; sépalas 4, desiguais, róseo-claras, escassamente pilosas na página dorsal, a adaxial mais larga e, às vezes, bilobada, cerca de $8 \mathrm{~mm}$ de comprimento, 2-2,5mm de largura, oblonga, obtusa no ápice, as 3 sépalas restantes com 7-10mm de comprimento, $1-2 \mathrm{~mm}$ de largura, mais ou menos lineares ou elíticas, agudas no ápice; pétalas 5 , desiguais, esparsamente pubescentes na parte dorsai, a adaxial amarela, obovada, ondulada marginalmente, atenuada na base em direção ao unguículo, a lâmina cơm $5-10 \mathrm{~mm}$ de comprimento, $4-7 \mathrm{~mm}$ de largura, 0 unguículo róseo-claro, cerca de $4-7 \mathrm{~mm}$ de comprimento, as 4 pétalas restantes subiguais, unguiculadas, estreitamente elíticas, acuminadas no ápice e atenuadas na base em direção ao unguículo, róseo-claras, lâminas de $7-15 \mathrm{~mm}$ de comprimento, $1-2 \mathrm{~mm}$ de largura; estames $8-10$, filamentos com $1,5-2,5 \mathrm{~cm}$ de comprimento, róseo-claros, vilosos na parte inferior, anteras glabras, oblongas, dorsifixas, cerca de $1,5 \mathrm{~mm}$ de comprimento; estigma peitado; estilete glabro, cerca de $7-20 \mathrm{~mm}$ de comprimento; ovário oblongo, com 5-6mm de comprimento, $1,5 \mathrm{~mm}$ de largura, densamente viloso; ginófore glabro com $3-4 \mathrm{~mm}$ de comprimento, unila-

(") - Instituto Nacional de Pesquisas da Amazônia, Manaus. 


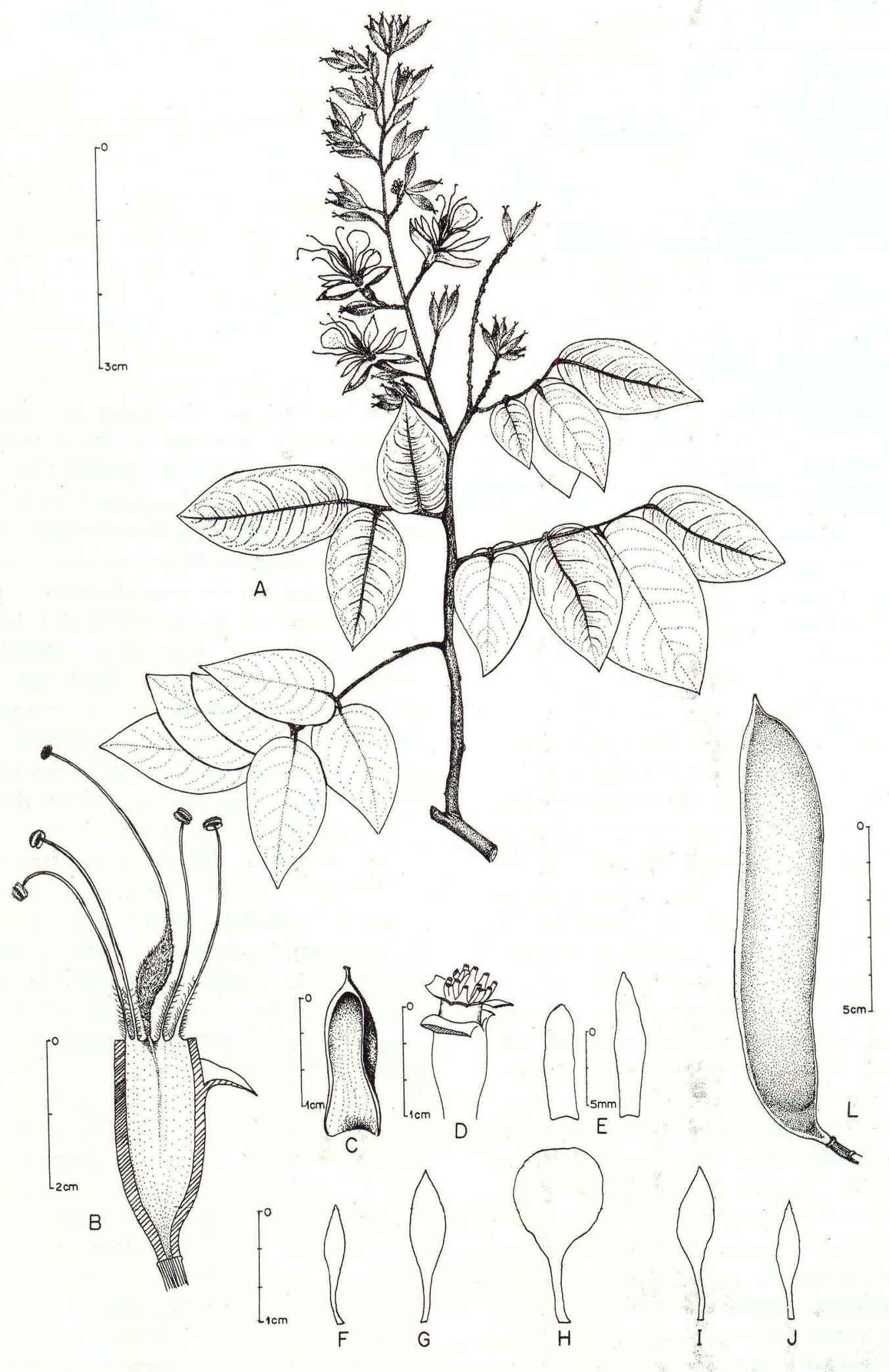

Fig. 1 - Dicymbe arenicola W. Rodr., n. sp. (W. Rodrigues \& J. Ramos 9630). A - ramo florífero; B - receptáculo seccionado longitudinalmente; C - bractéola; D - receptáculo; E - - sepalas; F, G, H, I e J - pétalas; L fruto. (O.P. Monteìro \& J.F. Ramos; 34). Desenho de Alberto Silva. 
terailmente inserto na superfície interna e ápical do hipanto; fruto com $11-12 \mathrm{~cm}$ de comprimento, $2,0-2,7 \mathrm{~cm}$ de largura, glabro, oblongo, levemente falcado, curtamente estipitado e bastante assimétrico na base e obliquamente acuminado no ápice pelo remanescente estilar, lateralmente comprimido, coriáceo-lenhoso, um tanto espassamente dilatado na sutura dorsal; até 7 sementes por fruto; apenas vistas sementes imaturas, oval-oblongas, comprimidas, lisas, pardas, $12-14 \mathrm{~mm}$ de comprimento, 7-10mm de largura.

TIPOS: - Brasil. Amazonas, estrada Manaus-Caracaraí, K 115 (antes Km 170 e 130), Campina das Pedras - Árvore pequena, freqüente na campina, em terra firme; raque floral verde; bractéolas acinzentadas, com 2 glândulas apicais roxas; cálice róseo-claro, pétalas róseo-claras, exceto a maior, com lâmina amarela e unguículo róseo-claro; estames livres, cremes, róseos apenas na metade inferior; ovário acinzentado. W. A. Rodrigues \& J. Ramos 9630, fl. 06 Ago. 1975 (holótipo: INPA 50220, madeira X-6138; isótipos: MG, IAN); ibidem, campina on white sandstone. Tree $4 \mathrm{~m}$ tall, 2 bracteoles, 4 calyx lobes, pale pink. Light scented 10 a.m. C. C. Berg, F. A. Bisby \& J. F. Ramos P18158, fI. 27 Set. 1973 (INPA 41463, NY, MG, R); ibídem: campinarana, solo arenoso úmido. Árvore de $6 \mathrm{~m}$ de alt., $10 \mathrm{~cm}$. de diâmetro, frutos imaturos. O. P. Monteirro \& J. F. Ramos 34 fr. 6 Jan. 1976 (INPA 54345); ibidem, campina adjacent to igarapé Lajes. Tree $4 \mathrm{~m}$ tall; flowers reddish-pink with yellow banner petal. J. L. Zarucchi, F. Almeida \& D. F. Coelho 2542, fl. 14 Set. 1979 (INPA 90013, NY).

Esta espécie distingue-se, principalmente de D. stipitata Cowan (1958), pelas seguintes características: folhas em geral menores; folíolo em 2-5 pares, subcordatos na base e com uma glândula no ápice; pétalas adaxıais suborbiculares ou obovadas; estames 8-10, com filamentos vilosos na metade inferior; e ovário densamente piloso.

Como na espécie mais afim, $D$. arenicola tem apenas 4 sépalas, sendo que as do par adaxial se apresentam em geral unidas em suas margens contíguas, formando apenas uma única sépala, maior, inteira, ou, às vezes, bilobada no ápice. Deve ser incluída na Seção Eremopetala de Cowan (1957) por ter apenas uma pétala bem desenvolvida e 4 outras um tanto reduzidas e diferentes, embora, como a primeira, todas elas fossem também distintamente unguiculadas .

\section{SUMIMARY}

Dicymbe arenicola W. Rodrigues is described in this paper as a new species of Leguminosae - Caesalpinioideae. This species is a small tree up to now only known from a white sandstone campina near Manaus, Brazil.

\section{BIBLIOGRAFIA}

COWAN, RICHARD S.

1957 - Leguminosae-Caesalpinioideae. In Mem. New York Bot. Garden 9 (3): 337-349.

1958 - Studies in Tropical American Leguminosae - IV. In Brittonia 10: 28-31.

(Aceìto para publicação em $11 / 06 / 80$ ) 